$$
\text { Conf }-9406131--28
$$

DOE/METC/C-94/7153

Desulfurization Sorbent Development at the Morgantown Energy Technology Center

Authors:

Siriwardane, Ranjani V. (METC)

Grimm, Ulrich NMN (METC)

Poston, James A. (METC)

Monaco, Steven J. (EG\&G Technical Services of West Virginia)

Conference Title:

Coal Fired Power Systems 94 --

Advances in IGCC and PFBC Review Meeting

Conference Location:

Morgantown, West Virginia

Conference Dates:

June 21-23, 1994

Conference Sponsor:

U.S. Department of Energy, Morgantown Energy Technology Center 


\section{DISCLAIMER}

This report was prepared as an account of work sponsored by an agency of the United States Government. Neither the United States Government nor any agency thereof, nor any of their employees, makes any warranty, express or implied, or assumes any legal liability or responsibility for the accuracy, completeness, or usefulness of any information, apparatus, product, or process disclosed, or represents that its use would not infringe privately owned rights. Reference herein to any specific commercial product, process, or service by trade name, trademark, manufacturer, or otherwise does not necessarily constitute or imply its endorsement, recommendation, or favoring by the United States Government or any agency thereof. The views and opinions of authors expressed herein do not necessarily state or reflect those of the United States Government or any agency thereof.

This report has been reproduced directly from the best available copy.

Available to DOE and DOE contractors from the Office of Scientific and Technical Information, 175 Oak Ridge Tumpike. Oak Ridge, TN 37831; prices available at (615) 576-8401.

Available to the public from the National Technical Information Service, U.S. Department of Commerce, 5285 Port Royal Road. Springfield, VA 22161; phone orders accepted at (703) $487-4650$. 


\section{DISCLAIMER}

Portions of this document may be illegible in electronic image products. Images are produced from the best available original document. 


\title{
Desulfurization Sorbent Development at the Morgantown Energy Technology Center
}

\author{
Ranjani V. Siriwardane \\ Ulrich Grimm \\ James Poston \\ Morgantown Energy Technology Center \\ Steven Monaco \\ EG\&G Technical Services of West Virginia
}

\section{OBJECTIVES}

The overall objective of this project is to develop regenerable sorbents for hot gas desulfurization in IGCC systems. The major criteria for the development of novel sorbents included reasonable chemical reactivity and physical . durability during repeated sulfidation and regeneration cycles.

\section{BACKGROUND}

Various formulations of zinc ferrite and zinc titanate in the form of extrudates and spherical pellets have been studied at the Morgantown Energy Technology Center (METC) for removal of sulfurous gases from coal gasification gas streams (Mei et al. 1993). Problems of decrepitation and spalling have occurred after sulfidation and regeneration of these sorbents. Z-Sorb, a proprietary sorbent developed at Phillips Petroleum Company, showed good physical durability during testing at METC, but there was a continuous decrease in reactivity during multiple cycle tests due to steam regeneration (Delzer et al. 1993). A series of novel sorbents containing zinc oxide have been developed at METC to address these problems. These METC-developed sorbents showed superior performance during a 20-cycle, high-pressure, fixed-bed test with steam regeneration conducted at METC.

\section{PROJECT DESCRIPTION}

Nine sorbents (METC1 through METC9) were prepared, but only some of these sorbents were selected for initial testing. The remaining sorbents will be tested in the future. Two of these sorbents (METC2 and METC6) have been tested both in the low-pressure and the highpressure reactors. Results of the high-pressure testing of METC2 and METC6 and low-pressure testing of METC7 will be discussed in this paper. METC2 and METC7 were designed for fixed-bed or moving-bed applications, while METC6 was designed for fluid-bed applications. However, these three sorbents were tested in a fixed bed. Twenty (20) cycles of sulfidation reactions were completed for METC2 and 15 sulfidation cycles were completed for METC6 in the high-pressure reactor. Five sulfidations were completed with METC7 in the low-pressure reactor.

Sorbents were prepared at METC by a solid-state mixing method utilizing a mixer pelletizer. The sorbents contained about $50 \mathrm{wt} \%$ of zinc oxide. The sorbents were initially tested in a low-pressure (272 $\mathrm{kPa} / 39.7$ psia) reactor. This quartz reactor had a diameter of $5.7 \mathrm{~cm}$ 
(2.2 inches) and a bed height of $15.2 \mathrm{~cm}$

( 6 inches). Sorbents that showed promising results in the low-pressure unit were then tested in the high-pressure, bench-scale, hot gas desulfurization unit at $1034 \mathrm{kPa} / 150 \mathrm{psia}$, which contains a 5.5-cm (2.2-inch) inner diameter reactor system. The reactor is constructed of Incoloy $800 \mathrm{HT}$ alloy steel shell. Inside the shell there is a removable 316 stainless steel cage for easy loading and unloading of the sorbent. The sorbent cage is suspended from the top flange of the reactor shell. A gas distributor is fixed at the bottom of the cage to support the sorbent. The inside of the sorbent cage is Alon-processed to prevent corrosion of stainless steel by sulfur gases in the presence of steam. The reactor is housed inside a three-zone furnace equipped with separate temperature controllers for each zone. Quartz wool was installed on top of the sorbent bed to hold the sorbent as well as to capture particulates from the fixed bed for upflow operation. The details of this system are reported by Mei et al. (1993).

A 40.7-cm (16-inch) deep fixed bed of sorbent was subjected to alternating periods of sulfidation and regeneration. Sulfidation was accomplished by feeding a gas, which simulated the expected $\mathrm{KRW}$ fuel gas composition, in a downflow mode through the reactor at $538^{\circ} \mathrm{C}$ $\left(1000^{\circ} \mathrm{F}\right)$. The sorbent regeneration was performed in the reverse direction (upflow), utilizing air diluted with nitrogen or nitrogen and steam in order to limit the regeneration exotherm and prevent overheating of the sorbent.

\section{RESULTS}

\section{High-Pressure Testing}

All the sulfidations in the high-pressure reactor were performed at $538^{\circ} \mathrm{C}\left(1000{ }^{\circ} \mathrm{F}\right)$ and $1034 \mathrm{kPa}$ (150 psia), utilizing a feed gas containing $800 \mathrm{ppmv}$ hydrogen sulfide $\left(\mathrm{H}_{2} \mathrm{~S}\right)$. The superficial velocity for all sulfidations in the high-pressure reactor was maintained at $0.3 \mathrm{~m} / \mathrm{s}$ $(1.0 \mathrm{ft} / \mathrm{s})$ and the space velocity was $1363 \mathrm{hr}^{-1}$. The outlet $\mathrm{H}_{2} \mathrm{~S}$ concentration was monitored using detector tubes and gas chromatography.

All regenerations in the high-pressure reactor were done at $170 \mathrm{kPa}$ (24.7 psia), and the gas velocity was maintained constant at $0.3 \mathrm{~m} / \mathrm{s}(1.0 \mathrm{ft} / \mathrm{s})$. All dry regenerations were performed utilizing a multi-stage technique. With nitrogen as a diluent gas, the oxygen concentration was increased in discrete increments from 0.5 mole $\%$ to 21 mole $\%$, while simultaneously increasing the bed temperature from 538 to $760^{\circ} \mathrm{C}\left(1000\right.$ to $\left.1400{ }^{\circ} \mathrm{F}\right)$. The exit gas was monitored for sulfur dioxide $\left(\mathrm{SO}_{2}\right)$ using detector tubes and gas chromatography. All regenerations were performed until the $\mathrm{SO}_{2}$ concentration dropped to less than 50 ppmv.

Steam regeneration was conducted in four stages. The temperatures of the four stages were $538,579,621,663{ }^{\circ} \mathrm{C}(1000,1075,1150$, and $1225^{\circ} \mathrm{F}$ ). The steam concentration in all four stages was 50\% with a varying concentration of oxygen and nitrogen. The oxygen concentration during the four stages was $0.5,2.5,4.0$, and $7.0 \%$ respectively.

\section{Results of the METC2 Testing in the High- Pressure Unit}

The results of the six sulfidation runs for METC2 performed utilizing dry regeneration in the high-pressure reactor are shown in Figure 1. There was a continuous increase in the sorbent sulfur capacity from sulfidation cycle 1 to cycle 5 , after which the capacity stabilized. A comparison of the sulfidation breakthrough curves for METC2 and for a molybdenumcontaining zinc titanate from General Electric Company tested under identical conditions is shown in Figure 2. For zinc titanate, there was a decrease in the sulfur capacity up to the third 


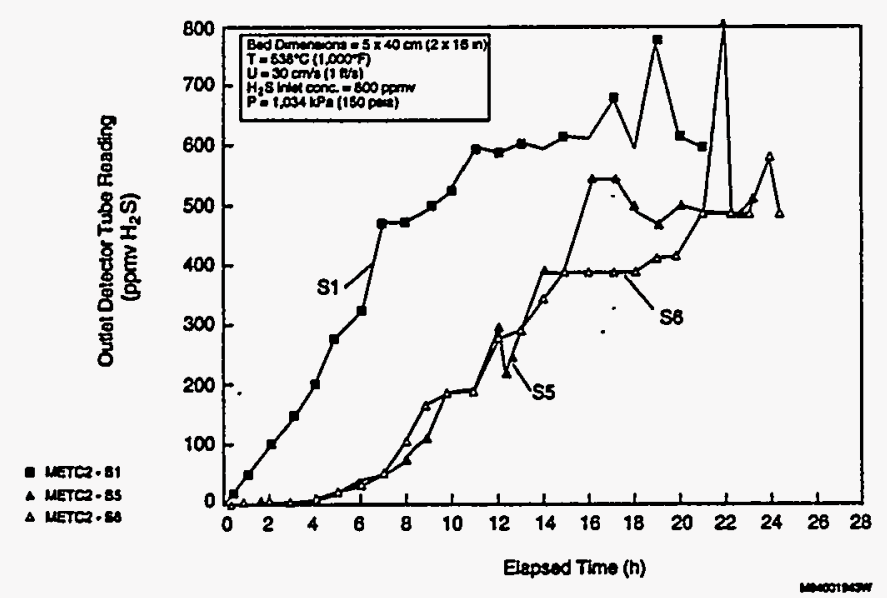

Figure 1. METC2 Sorbent Sulfidations 1 Through 6

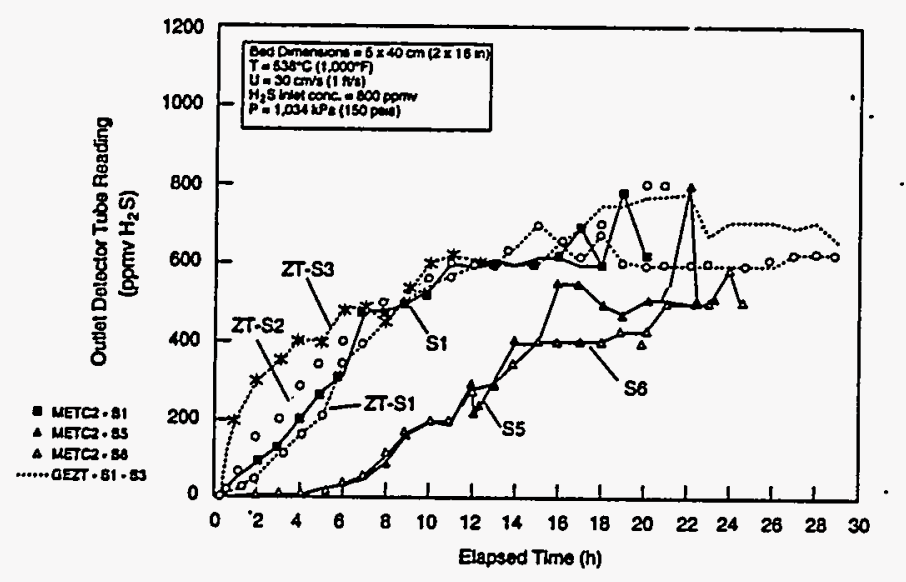

Figure 2. Sulfidations of METC2 Sorbent and GE Zinc Titanate

cycle, and the sorbent stabilized after the third cycle. The sulfur capacity of METC2 after it stabilized at cycle 5 was significantly better than that of the zinc titanate. A comparison of the sulfidation breakthrough curves for METC2 and Z-Sorb from Phillips Petroleum are shown in Figure 3. The sulfur capacity for METC2 after it stabilized at the fifth cycle is comparable to that of Z-Sorb.

In order to understand how steam regeneration would affect the performance of the METC2 sorbent, regenerations during cycles 6

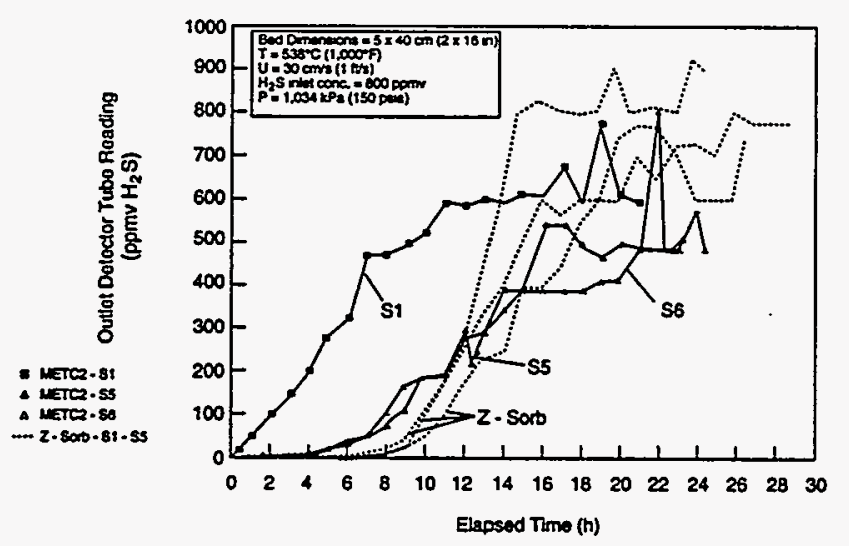

Figure 3. Sulfidations of METC2 Sorbent and Z-Sorb from Phillips Petroleum

through 19 were conducted utilizing steam. The sulfidation breakthrough curves from sulfidations 7 through 20 (which all follow steam regenerations) are shown in Figure 4. There was a slight decrease in the sulfur capacity between the sixth (last sulfidation following dry regeneration) and seventh sulfidation (first sulfidation following steam regeneration). However, the breakthrough curves for sulfidations 7 to 11 overlapped,

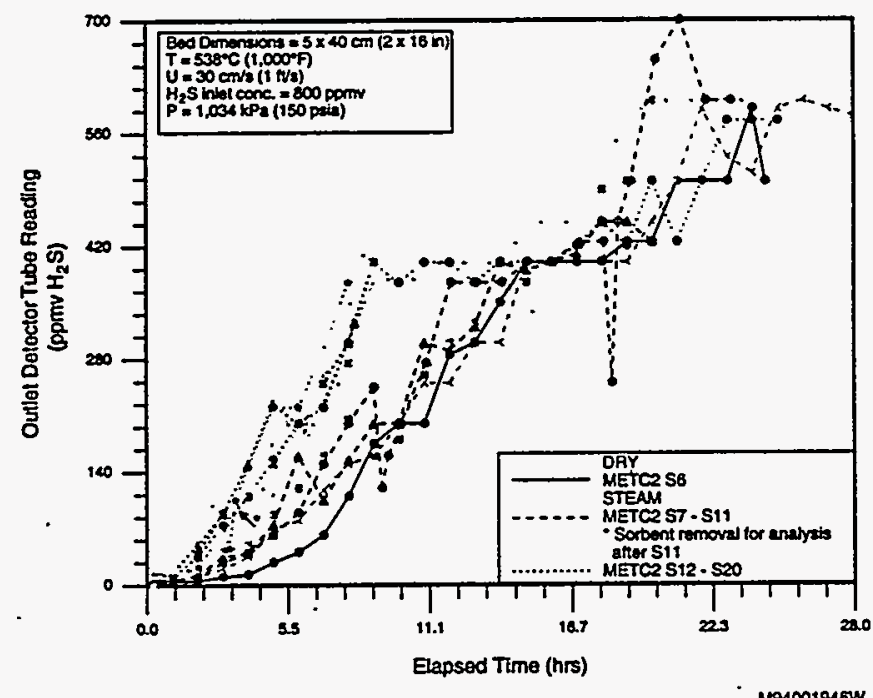

Figure 4. Effect of Steam Regeneration on on METC2 Sorbent During 20-Cycle Testing 
indicating that the steam regeneration did not affect the sorbent.

After the eleventh sulfidation some of the sorbent was removed from the reactor for total sulfur analysis. The decrease in breakthrough time between sulfidations 11 and 12 is due to the removal of this material from the sorbent bed. The sulfidation breakthrough curves from cycles 12 to 20 , which also follow steam regenerations, overlapped as well, indicating that the sorbent was stable during steam regeneration. The percent total sulfur content from the solid analysis of the sorbent after the 20th cycle was similar to that after the 11th cycle. This further confirmed that the decrease in sulfur capacity during the 11th and 12th cycles was due to the sorbent removal. There was no change observed in the sulfur absorption capacity caused by the steam regenerations in the 7th through 20th sulfidation cycles.

The visual examination of the sorbent after 20 sulfidations indicated that there was no spalling or any other physical deterioration of the sorbent. The crush strength of the sorbent after 20 cycles was higher than that of the fresh sample. Sieve analysis indicated that $92 \%$ of the material was unaffected after 20 cycles. This is even after dropping the sorbent in from the top of the reactor during the initial loading and utilizing a vacuum cleaner for sorbent removal from the bed. All of the condensates collected during the 20-cycle test were very clear, indicating that the sorbent did not decrepitate in the bed and that there was no powder lost from the sorbent as observed with zinc ferrite or zinc titanate. The zinc content detected in the condensates was negligible. The METC2 sorbent showed a superior level of performance during the 20-cycle, high-pressure, fixed-bed testing. It is spalling.resistant, steam resistant, and had both excellent chemical and physical durability during the 20-cycle test.
Results of METC6 Testing in the HighPressure Unit

The chemical formulation of METC6 was designed for fluid-bed applications, but the pellets were sized for the testing which was conducted in a fixed bed. Fifteen (15) sulfidation cycles were completed with METC6 in the high-pressure unit utilizing steam regeneration. This test series will be continued for up to a total of 20 sulfidation cycles. The sulfidation breakthrough curves of METC6 are shown in Figure 5. There was an increase in sorbent sulfur capacity between sulfidations 1 and 2 , but the capacity decreased again at the third sulfidation cycle. The sulfidation breakthrough curves from the 3rd to 15th cycle overlapped, with a slight decline seen in cycles 14 and 15. This indicates that the sorbent was chemically stable during the 15 cycles of testing and was not affected adversely by the steam regeneration. The condensates collected from the reactor during this test series were very clear. Even though METC6 was formulated for fluid-bed applications, it performed very well with the bigger particle sizes required in fixed-bed testing.

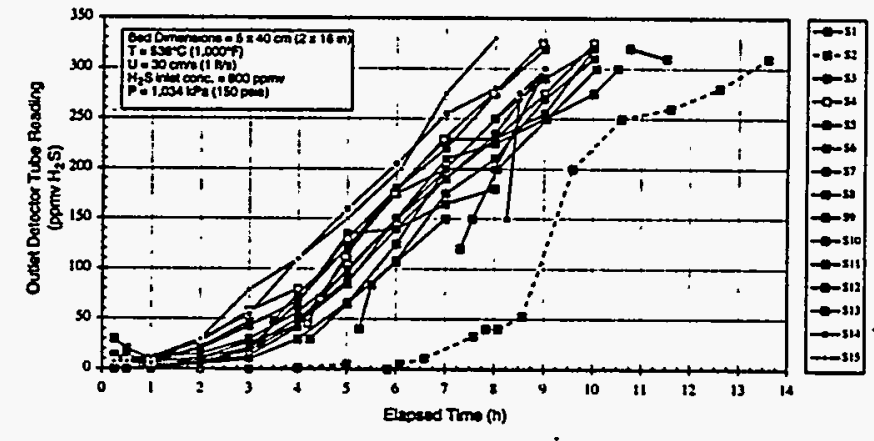

Figure 5. Sulfidations of METC6 Utilizing Steam Regeneration 
Results of the METC7 Testing in the LowPressure Unit

All of the sulfidations in the low-pressure reactor were performed at $538^{\circ} \mathrm{C}\left(1000{ }^{\circ} \mathrm{F}\right)$ and $260 \mathrm{kPa}$ (38 psia), utilizing a feed gas containing $2000 \mathrm{ppmv} \mathrm{H}_{2} \mathrm{~S}$. The superficial velocity for all sulfidations in the low-pressure reactor was maintained at $0.09 \mathrm{~m} / \mathrm{s}(0.30 \mathrm{ft} / \mathrm{s})$ and the space velocity was $2000 \mathrm{~h}^{-1}$. The outlet $\mathrm{H}_{2} \mathrm{~S}$ concentration was monitored using detector tubes and gas chromatography.

All regenerations in the low-pressure reactor were done at $272 \mathrm{kPa}$ (39.7 psia) and the gas velocity was maintained constant during each stage at 0.04 to $0.05 \mathrm{~m} / \mathrm{s}(0.13$ to $0.15 \mathrm{ft} / \mathrm{s})$. The steam regenerations were conducted in three stages. The temperatures of the stages were. 538,593 , and $649^{\circ} \mathrm{C}(1000,1100$, and $1200^{\circ} \mathrm{F}$ ). The steam concentration in all three stages was $50 \%$, with a varying concentration of oxygen and nitrogen. The oxygen concentrations during the three stages were 1.0, 2.5, and $3.5 \%$, respectively.

The sulfidation breakthrough curves of METC7 in the low pressure unit are shown in Figure 6. There was an increase in sulfur capacity from sulfidation 1 to 2 , but the sulfur capacity decreased in the third sulfidation. The sulfidation breakthrough curves overlapped after the third sulfidation, indicating sorbent stabilization at that point. As shown in Figure 6, the outlet hydrogen sulfide concentration was zero for about 15 hours, indicating that the efficiency of the sorbent was excellent. A comparison of METC6 and METC7 tested in the low-pressure unit is shown in Figure 7. It is clear that the sulfur capacity of METC7 is better than that of METC6. Since METC7 was the fixed-bed version of METC 6 , it was expected to have a better capacity in fixed-bed testing. Visual examination of the METC7 sorbent after the fifth cycle

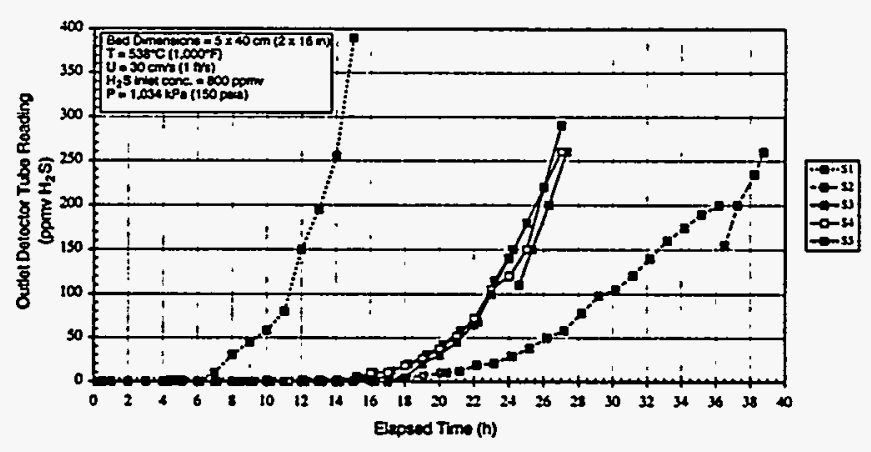

\section{Figure 6. Sulfidations of METC7 Utilizing Steam Regeneration}

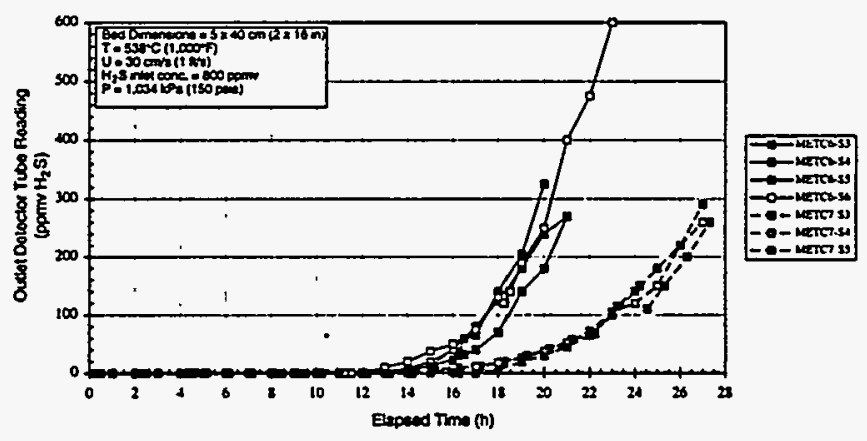
Figure 7. Sulfidations of METC6 and
METC7

indicated that there was no spalling or any other signs of physical deterioration during the testing.

\section{FUTURE WORK}

1. The testing of METC6 in the high-pressure reactor will be continued for a total of 20 cycles.

2. METC2 will be tested using actual coal gas as the feed gas. 
3. Other METC formulations will be tested in the thermogravimetric analysis (TGA) and in the low-pressure unit in order to optimize the formulations.

4. The sorbents will be tested in other types of reactors, such as a fluid-bed, movingbed, or transport reactor.

5. A Cooperative Research and Development Agreement (CRADA) will be initiated.

6. The optimum sorbent may be tested in a Clean Coal Technology demonstration plant.

\section{REFERENCES}

Mei, J.S., L.D. Gasper-Galvin, C.E. Everitt, and S. Katta. 1993. Fixed-Bed Testing of a Molybdenum-Promoted Zinc Titanate Sorbent for Hot Gas Desulfurization. In Proceedings of the Coal-Fired Power Systems 93 -- Advances in IGCC and PPBC Review Meeting, 315-325. DOE/METC-93/6131. NTIS/DE93000289. Springfield, Va.: National Technical Information Service.

Delzer, G.A., G.P. Khare, and G.J. Greenwood. 1993. Z-Sorb Absorbent for Hot Gas Desulfurization. AIChE Annual Meeting, St. Louis, Missouri. Symposium on Gas Purification, Paper No. $130 \mathrm{f}$.

\section{ACKNOWLEDGMENTS}

The authors would like to acknowledge all the members of the Sorbent Development Cluster at the Morgantown Energy Technology Center (METC) for their contributions to this project as well as the members of EG\&G, the prime support contractor at METC, who conducted the sorbent reactor testing. 